\title{
Evaporation trends in Spain: a comparison of Class A pan and Piché atmometer measurements
}

\author{
A. Sanchez-Lorenzo ${ }^{1,2, *}$, S. M. Vicente-Serrano ${ }^{2}$, M. Wild ${ }^{3}$, J. Calbó ${ }^{1}$, \\ C. Azorin-Molina ${ }^{2}$, J. Peñuelas ${ }^{4,5}$ \\ ${ }^{1}$ Department of Physics, University of Girona, 17071 Girona, Spain \\ ${ }^{2}$ Instituto Pirenaico de Ecología, Consejo Superior de Investigaciones Científicas (IPE-CSIC), 50059 Zaragoza, Spain \\ ${ }^{3}$ Institute for Atmospheric and Climate Science, ETH Zurich, 8092 Zurich, Switzerland \\ ${ }^{4}$ CSIC, Global Ecology Unit CREAF-CSIC-UAB, Cerdanyola del Vallès, 08193 Catalonia, Spain \\ ${ }^{5}$ CREAF, Cerdanyola del Vallès, 08193 Catalonia, Spain
}

\begin{abstract}
Interest is growing in the trends of atmospheric evaporation demand, increasing the need for long-term time series. This work describes, for the first time, the development of a dataset on evaporation in Spain based on long-term series of Piché and pan measurement records. Piché measurements have been reported for $>50$ stations since the 1960s. Measurements of pan evaporation, which is a much more widely studied variable in the literature, are also available, but only since 1984 for 21 stations. Particular emphasis was placed on the homogenization of this dataset. Both the mean annual Piché and pan series over Spain showed evaporative increases during the common study period (1985-2011), by a rate of around $+0.1 \mathrm{~mm} \mathrm{~d}^{-1}$ decade $^{-1}$. Furthermore, using the annual Piché records since the 1960s, an evaporation decline was detected from the 1960s to the mid-1980s, which resulted in a non-significant trend over the entire 1961-2011 period. Our results indicate agreement between the decadal variability of reference evapotranspiration and the surface solar radiation previously reported and the evaporation from Piché and pan measurements, especially during summer. The suitability of Piché records compared to pan evaporation data to represent past trends is discussed.
\end{abstract}

KEY WORDS: Piché evaporimeter $\cdot$ Pan evaporation $\cdot$ Trends $\cdot$ Spain

Resale or republication not permitted without written consent of the publisher

\section{INTRODUCTION}

Surface evaporation plays a crucial role in the hydrological cycle that is an essential component of the climate system and has significant biological, environmental and socio-economic impacts (e.g. Peñuelas et al. 2013). Consequently, trends in evaporation are a key factor in the study of the intensity of the water cycle. Nevertheless, evaporation measurements, which are mainly performed using pan evaporation devices, present some limitations (Fu et al. 2009) due to uncertainties in the measurements and other sources of error (Abtew et al. 2011).

A widespread decrease in pan evaporation has been observed since the 1950s (e.g. Peterson et al. 1995, Roderick \& Farquhar 2002, 2004); this stands in contrast to the increase in temperatures that has occurred in the last few decades, and results in an evaporation paradox for which different hypotheses have been formulated (Brutsaert \& Parlange 1998, Hobbins et al. 2004, Fu et al. 2009, Matsoukas et al. 2011, McVicar et al. 2012). Consequently, a comparison of pan evaporation data with other estimates of atmospheric evaporative demand (McMahon et al. 2013) is needed in order to use these data as a proxy measure for evaporative demand. Equally, an analysis of measurements of the less well-known Piché evaporimeter (De Vries \& Venema 1954, WMO 2008) to assess decadal changes in evaporation, as an alternative to pan evaporation data, has not yet been performed to our knowledge. 
Nevertheless, some of the most important drawbacks when studying the trends of pan evaporation are the lack of long-term series in large areas of the world (e.g. Africa and South America), the limited number of measuring stations, even in areas such as Europe and North America, and the fact that most of the series are only available for the period after the 1970s (McVicar et al. 2012). In Europe there are a few studies reporting trends in pan evaporation for the UK, Ireland and Greece, with less than about 30 stations in all these countries together (McVicar et al. 2012). In addition, another confounding issue is the lack of comprehensive evaluation of the homogeneity of the series (Jovanovic et al. 2008).

In Spain, on the whole, some attempts have recently been made to study the trends in reference evapotranspiration $\left(\mathrm{ET}_{0}\right)$. Indeed, Vicente-Serrano et al. (2014b) showed a general increase, especially in summer, in the $\mathrm{ET}_{0}$ over Spain from 1961 to 2011 by using various semi-empirical methods, including the FAO-Penman-Monteith equation, which incorporates calculations based on a homogeneous series of data on temperature, wind speed, relative humidity and sunshine duration. Nevertheless, an analysis of the pan evaporation and Piché series available for Spain is still lacking.

The objective of this study was to generate a dataset of homogeneous Piché and pan evaporation series for Spain, and to compare both types of records and study their temporal changes.

\section{DATA AND METHODS}

\subsection{Dataset}

The evaporation dataset in Spain up to December 2011 (the last year considered in this study) was obtained from the Spanish Agencia Estatal de Meteorología (AEMET). It contains daily records of Piché and Class A pan evaporation, expressed in millimeters. It is worth noting that the values of both instruments are not strictly comparable, as the depth of water evaporated from the water surface of the pan is physically meaningful, while the volume evaporated from the reservoir of the Piché atmometer is not, due to the characteristics of the instrument (see below).

Class A pan evaporimeters are the most widely used type of evaporimeters to perform measurements of evaporation and to study evaporative demand (McVicar et al. 2012). In brief, the Class A pan is a cylindrical tank of galvanized iron, around $120 \mathrm{~cm}$ in diameter and $25 \mathrm{~cm}$ deep, mounted on an open wooden platform. The pan is filled with water to a few centimeters below the rim, and the daily evaporation rate is measured by manual readings, refilling the water level if needed, or reducing the content of water if rain has caused the tank to overflow (WMO 2008).

Albert Piché was a French inventor who designed the first Piché evaporimeter (or atmometer) in the $1870 \mathrm{~s}$; since then the instrument has been used in several countries (e.g. Prescott \& Stirk 1951, Stanhill 1962, Papaioannou et al. 1996). In Spain, we have evidence of atmometer measurements since the second half of the 19th century for at least 20 meteorological stations, as is shown, for example, in a summary of the publication entitled 'Resumen de las observaciones meteorológicas efectuadas en la Peninsula', edited by the Spanish weather service from 1865 to 1950 . Unfortunately, these data are not currently available in digital format. The Piché evaporimeter consists of a $3 \mathrm{~cm}$ diameter disc of filter paper held by a metal clip to the bottom of an inverted graduated cylindrical tube of $1.5 \mathrm{~cm}$ in diameter, which supplies deionized water to the disc. Thus, the water evaporates from the surface of the filter paper. Daily measurements of the volume of water remaining in the graduated tube give the amount lost by evaporation in millimeters, with a measuring accuracy of $0.1 \mathrm{~mm}$. The Piché atmometer is usually exposed inside a meteorological screen together with other meteorological instruments (WMO 2008).

In Spain, the first available Piché measurements in digital format correspond to 1907, with around 10 stations available in the $1940 \mathrm{~s}$, and $>100$ after the 1960s, most of them, however, with data covering only the last 2 decades; so, the average series length is only $10 \mathrm{yr}$. As far as pan evaporation measurements are concerned, only around 30 stations provide data covering $>15$ yr. For the present study, only Piché and pan long-term series starting, at the latest, in the early 1960s and 1980s, respectively, were selected. Taking into account the above-mentioned considerations, the final dataset consists of 56 Piché and 21 pan evaporation series representing a distribution across Spain. Specifically, all the considered Piché (pan) series were available since 1961 (1984), and measurements from both Piché and pan evaporation series were available for 19 stations (for more details see Table 1 and Fig. 1).

\subsection{Homogenization of the dataset}

Before applying the homogeneity test, the data were quality controlled to identify anomalous or ques- 
tionable records in the series. For this purpose we followed the procedure based on a comparison of the rank of each data record and the average rank of the data recorded at adjacent stations (Vicente-Serrano et al. 2010). After testing different thresholds, the maximum allowed difference between a candidate observation and the average values of the percentiles at the neighbouring observatories was set at 40 percentile units. If the difference was higher than this, the candidate observation was considered questionable and the value was flagged.

Inhomogeneities are common in climate data series due to changes in station location, alteration of the surrounding environment, observer changes and instrument replacement (Peterson et al. 1998). If a series is identified as non-homogeneous, the use of the data for trend and variability analyses becomes questionable, and the series is usually discarded. Relative homogeneity methods are commonly recommended to identify temporal homogeneity in climate series (Venema et al. 2012). Specifically, in relative homogeneity testing, the temporal evolution of a candidate series is compared to a reference series created from nearby correlated series, or by testing each candidate series against other series (Peterson et al. 1998, Venema et al. 2012).

In this study, we have used a recently developed method (HOMER-HOMogenization software in R) developed within the framework of the European COST Action ES0601 (www.homogenisation.org/) that compares each candidate series with a number of available series without the need of creating a reference series (Mestre et al. 2013). HOMER is a semi-automatic methodology, which combines a partly subjective pairwise comparison with a fully automatic joint-segmentation method.

Firstly, the 8 stations closest to a candidate station were selected to check possible inhomogeneities. Then, the candidate series was compared to its neighbours by computing series of differences. This pairwise comparison was run with the annual data, and used ratios as a measure for comparisons. On such a difference series, if a detected change-point remains constant throughout most of the set of comparisons, it can be at-
Table 1. Details of the stations in Spain where the Piché and pan evaporation data were collected

\begin{tabular}{|c|c|c|c|c|c|}
\hline Station & Longitude & Latitude & Altitude (m) & Piché & Pan \\
\hline Albacete & $1.86^{\circ} \mathrm{W}$ & $38.95^{\circ} \mathrm{N}$ & 704 & $\mathbf{X}$ & \\
\hline Alicante airport & $0.56^{\circ} \mathrm{W}$ & $38.29^{\circ} \mathrm{N}$ & 31 & $\mathbf{X}$ & \\
\hline Alicante & $0.49^{\circ} \mathrm{W}$ & $38.37^{\circ} \mathrm{N}$ & 82 & $\mathbf{X}$ & \\
\hline Almería & $2.39^{\circ} \mathrm{W}$ & $36.84^{\circ} \mathrm{N}$ & 20 & $\mathbf{X}$ & $\mathbf{X}$ \\
\hline Avilés airport Asturias & $6.03^{\circ} \mathrm{W}$ & $43.56^{\circ} \mathrm{N}$ & 127 & $\mathbf{X}$ & \\
\hline Badajoz & $6.83^{\circ} \mathrm{W}$ & $38.88^{\circ} \mathrm{N}$ & 185 & $\mathbf{X}$ & \\
\hline Barcelona airport & $2.08^{\circ} \mathrm{E}$ & $41.30^{\circ} \mathrm{N}$ & 6 & $\mathbf{X}$ & \\
\hline Barcelona & $2.12^{\circ} \mathrm{E}$ & $41.42^{\circ} \mathrm{N}$ & 420 & $\mathbf{X}$ & \\
\hline Bilbao & $2.91^{\circ} \mathrm{W}$ & $43.30^{\circ} \mathrm{N}$ & 39 & & $\mathbf{X}$ \\
\hline Burgos airport & $3.63^{\circ} \mathrm{W}$ & $42.36^{\circ} \mathrm{N}$ & 890 & $\mathbf{X}$ & $\mathbf{X}$ \\
\hline Cáceres & $6.34^{\circ} \mathrm{W}$ & $39.47^{\circ} \mathrm{N}$ & 405 & $\mathbf{X}$ & $\mathbf{X}$ \\
\hline Cádiz & $6.26^{\circ} \mathrm{W}$ & $36.50^{\circ} \mathrm{N}$ & 8 & $\mathbf{X}$ & \\
\hline Castellón & $0.02^{\circ} \mathrm{W}$ & $39.95^{\circ} \mathrm{N}$ & 35 & $\mathbf{X}$ & \\
\hline Córdoba & $4.85^{\circ} \mathrm{W}$ & $37.84^{\circ} \mathrm{N}$ & 91 & $\mathbf{X}$ & \\
\hline Coruña & $8.42^{\circ} \mathrm{W}$ & $43.37^{\circ} \mathrm{N}$ & 58 & $\mathbf{X}$ & $\mathbf{X}$ \\
\hline Ciudad Real & $3.92^{\circ} \mathrm{W}$ & $38.99^{\circ} \mathrm{N}$ & 627 & $\mathbf{X}$ & $\mathbf{X}$ \\
\hline Cuenca & $2.14^{\circ} \mathrm{W}$ & $40.07^{\circ} \mathrm{N}$ & 956 & $\mathbf{X}$ & $\mathbf{X}$ \\
\hline Daroca & $1.41^{\circ} \mathrm{W}$ & $41.11^{\circ} \mathrm{N}$ & 779 & $\mathbf{X}$ & \\
\hline Gijón & $5.64^{\circ} \mathrm{W}$ & $43.54^{\circ} \mathrm{N}$ & 3 & $\mathbf{X}$ & \\
\hline Girona & $2.76^{\circ} \mathrm{E}$ & $41.90^{\circ} \mathrm{N}$ & 127 & $\mathbf{X}$ & \\
\hline Granada airport & $3.78^{\circ} \mathrm{W}$ & $37.19^{\circ} \mathrm{N}$ & 570 & $\mathbf{X}$ & $\mathbf{X}$ \\
\hline Granada air base & $3.63^{\circ} \mathrm{W}$ & $37.14^{\circ} \mathrm{N}$ & 685 & $\mathbf{X}$ & \\
\hline Huelva & $6.91^{\circ} \mathrm{W}$ & $37.28^{\circ} \mathrm{N}$ & 19 & $\mathbf{X}$ & $\mathbf{X}$ \\
\hline Huesca & $0.33^{\circ} \mathrm{W}$ & $42.08^{\circ} \mathrm{N}$ & 541 & $\mathbf{X}$ & \\
\hline Jerez de la Frontera & $6.06^{\circ} \mathrm{W}$ & $36.75^{\circ} \mathrm{N}$ & 27 & $\mathbf{X}$ & \\
\hline León & $5.65^{\circ} \mathrm{W}$ & $42.59^{\circ} \mathrm{N}$ & 916 & & $\mathbf{X}$ \\
\hline Lleida & $0.60^{\circ} \mathrm{E}$ & $41.63^{\circ} \mathrm{N}$ & 192 & $\mathbf{X}$ & $\mathbf{X}$ \\
\hline Logroño & $2.33^{\circ} \mathrm{W}$ & $42.45^{\circ} \mathrm{N}$ & 352 & $\mathbf{X}$ & \\
\hline Madrid Cuatro Vientos & $3.79^{\circ} \mathrm{W}$ & $40.38^{\circ} \mathrm{N}$ & 687 & $\mathbf{X}$ & $\mathbf{X}$ \\
\hline Madrid Getafe & $3.72^{\circ} \mathrm{W}$ & $40.30^{\circ} \mathrm{N}$ & 617 & $\mathbf{X}$ & \\
\hline Madrid Retiro & $3.68^{\circ} \mathrm{W}$ & $40.41^{\circ} \mathrm{N}$ & 667 & $\mathbf{X}$ & \\
\hline Málaga & $4.49^{\circ} \mathrm{W}$ & $36.67^{\circ} \mathrm{N}$ & 7 & $\mathbf{X}$ & $\mathbf{X}$ \\
\hline Morón de la Frontera & $5.62^{\circ} \mathrm{W}$ & $37.16^{\circ} \mathrm{N}$ & 87 & $\mathbf{X}$ & \\
\hline Murcia-Alcantarilla & $1.23^{\circ} \mathrm{W}$ & $37.96^{\circ} \mathrm{N}$ & 85 & $\mathbf{X}$ & \\
\hline Murcia & $1.17^{\circ} \mathrm{W}$ & $38.00^{\circ} \mathrm{N}$ & 62 & $\mathbf{X}$ & $\mathbf{x}$ \\
\hline Murcia-San Javier & $0.80^{\circ} \mathrm{W}$ & $37.79^{\circ} \mathrm{N}$ & 2 & $\mathbf{X}$ & \\
\hline Ourense & $7.86^{\circ} \mathrm{W}$ & $42.33^{\circ} \mathrm{N}$ & 143 & $\mathbf{X}$ & $\mathbf{X}$ \\
\hline Ponferrada & $6.60^{\circ} \mathrm{W}$ & $42.56^{\circ} \mathrm{N}$ & 534 & $\mathbf{X}$ & \\
\hline Reus & $1.16^{\circ} \mathrm{E}$ & $41.15^{\circ} \mathrm{N}$ & 73 & $\mathbf{X}$ & \\
\hline Salamanca & $5.50^{\circ} \mathrm{W}$ & $40.95^{\circ} \mathrm{N}$ & 790 & $\mathbf{X}$ & $\mathbf{X}$ \\
\hline Santiago de Compostela & $8.43^{\circ} \mathrm{W}$ & $42.90^{\circ} \mathrm{N}$ & 364 & $\mathbf{X}$ & $\mathbf{X}$ \\
\hline San Sebastián airport & $1.79^{\circ} \mathrm{W}$ & $43.36^{\circ} \mathrm{N}$ & 8 & $\mathbf{X}$ & \\
\hline San Sebastián & $2.04^{\circ} \mathrm{W}$ & $43.31^{\circ} \mathrm{N}$ & 252 & $\mathbf{X}$ & $\mathbf{X}$ \\
\hline Santander airport & $3.82^{\circ} \mathrm{W}$ & $43.43^{\circ} \mathrm{N}$ & 6 & $\mathbf{X}$ & \\
\hline Santander & $3.80^{\circ} \mathrm{W}$ & $43.49^{\circ} \mathrm{N}$ & 52 & $\mathbf{X}$ & \\
\hline Segovia & $4.13^{\circ} \mathrm{W}$ & $40.95^{\circ} \mathrm{N}$ & 1005 & $\mathbf{X}$ & \\
\hline Sevilla & $5.90^{\circ} \mathrm{W}$ & $37.42^{\circ} \mathrm{N}$ & 26 & $\mathbf{X}$ & \\
\hline Soria & $2.47^{\circ} \mathrm{W}$ & $41.77^{\circ} \mathrm{N}$ & 1082 & $\mathbf{X}$ & \\
\hline Toledo & $4.05^{\circ} \mathrm{W}$ & $39.88^{\circ} \mathrm{N}$ & 516 & $\mathbf{X}$ & $\mathbf{X}$ \\
\hline Tortosa & $0.49^{\circ} \mathrm{E}$ & $40.82^{\circ} \mathrm{N}$ & 48 & $\mathbf{X}$ & \\
\hline Valencia airport & $0.47^{\circ} \mathrm{W}$ & $39.49^{\circ} \mathrm{N}$ & 57 & $\mathbf{X}$ & \\
\hline Valencia & $0.38^{\circ} \mathrm{W}$ & $39.48^{\circ} \mathrm{N}$ & 11 & $\mathbf{X}$ & $\mathbf{X}$ \\
\hline Valladolid airport & $4.85^{\circ} \mathrm{W}$ & $41.70^{\circ} \mathrm{N}$ & 846 & $\mathbf{X}$ & $\mathbf{X}$ \\
\hline Valladolid & $4.77^{\circ} \mathrm{W}$ & $41.65^{\circ} \mathrm{N}$ & 735 & $\mathbf{X}$ & \\
\hline Vigo & $8.63^{\circ} \mathrm{W}$ & $42.22^{\circ} \mathrm{N}$ & 255 & $\mathbf{X}$ & \\
\hline Vitoria & $2.72^{\circ} \mathrm{W}$ & $42.88^{\circ} \mathrm{N}$ & 508 & $\mathbf{X}$ & \\
\hline Zamora & $5.73^{\circ} \mathrm{W}$ & $41.52^{\circ} \mathrm{N}$ & 656 & $\mathbf{X}$ & \\
\hline Zaragoza & $1.01^{\circ} \mathrm{W}$ & $41.66^{\circ} \mathrm{N}$ & 247 & $\mathbf{X}$ & \\
\hline
\end{tabular}




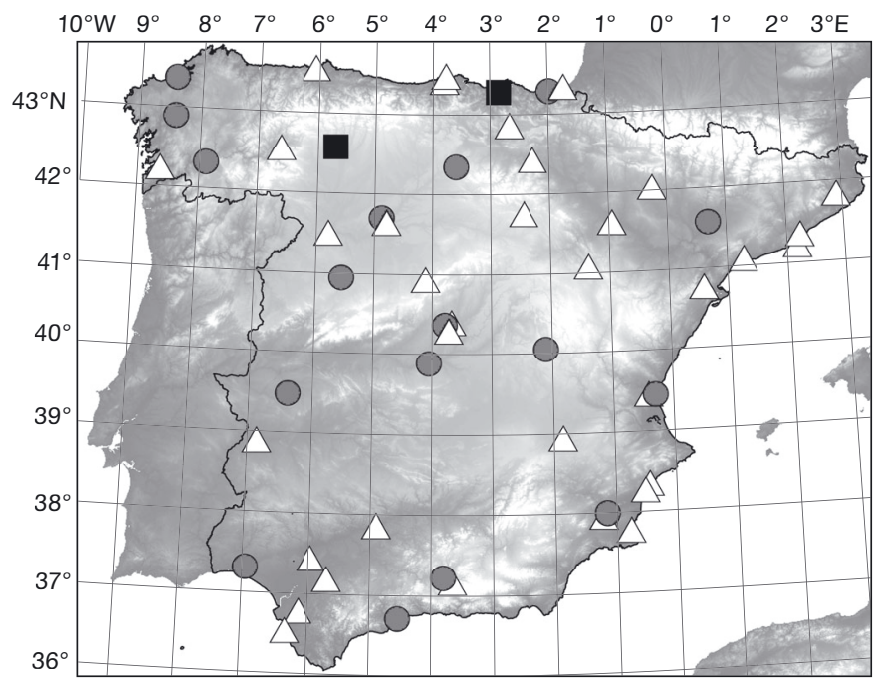

Fig. 1. Station location in Spain with evaporation series from both Piché and pan measurements (circles), as well as for Piché (triangles) or pan (squares) records only

tributed to a break in the candidate station, indicating a high probability of inhomogeneity. Thus, if a break point is identified between one station and several of its neighbours during the same year, we can say that inhomogeneity probably exists in the series. Finally, HOMER implements an automatic jointsegmentation method (for more details, see Mestre et al. 2013) in order to help determine significant break points. Fig. 2 shows the Almeria station as an example; pairwise comparison detected a potential break point between the Piché evaporation data in Almeria and its neighbouring observatories in 1991 (only the first 5 neighbour series are shown). Other breaks were also identified, but only for individual stations. The joint-segmentation function (not shown) confirmed that inhomogeneity existed in 1991.

The approach was applied to each of the available Piché and pan evaporation series, and, in a next step, HOMER corrected the inhomogeneities and completed missing values following Eq. (8) in Mestre et al. (2013). The procedure was iterated twice to eliminate possible inhomogeneities introduced when filling in missing values.

\subsection{Data analysis}

In this study, the annual, seasonal and monthly mean series for the whole of Spain were computed as an arithmetic mean of all available data. The seasons were defined as spring (MAM), summer (JJA), autumn (SON) and winter (DJF). The use of composite series enhances the signal-to-noise ratio, which permits better identification of decadal variations in the time series, as well as reduction of noise and biases due to regional features. The mean time series, which is discussed in Section 3.2, were smoothed by an 11 yr Gaussian low-pass filter, which improves the visualization of the decadal variability when the series are plotted together. The filter only takes into account the values on one side, at the beginning and end of the time series, in order to smooth data for the whole period.

The linear trends in the series were calculated by means of Sen's slope estimator, which is more robust than the least-squares method (Sen 1968), and their significance (at the $90 \%$ or greater confidence level) was estimated by the Mann-Kendall nonparametric test.

\section{COMPARISON OF PICHE AND PAN DATA}

\subsection{Comparison of the mean values}

Annual, seasonal and monthly mean absolute series for the whole of Spain were computed (for the period 1985-2011 due to data availability) by using the subset of 19 series with measurements of both types. In addition, mean annual and seasonal series considering the whole set of 56 Piché series were also computed for the same period.

Table 2 shows the annual and seasonal climatological means of Piché and pan evaporation for the mean series computed with the 19 stations, together with their standard deviations. Although the values of both measurements are not directly comparable (see Section 2.1), interestingly, both Piché and pan evaporation series showed similar annual mean and standard deviation values of around $3.8 \mathrm{~mm} \mathrm{~d}^{-1}$ (or $1400 \mathrm{~mm} \mathrm{yr}^{-1}$ ) and $0.20 \mathrm{~mm} \mathrm{~d}^{-1}$, respectively. These annual mean values were higher than the $\mathrm{ET}_{0}$ estimates for Spain using the Penman-Monteith equation (Allen et al. 1998), and similar to the ones produced by the Linacre (Linacre 1977) and the FAO-Blaney-Criddle (Doorenbos \& Pruitt 1977) equations (for more details, see Vicente-Serrano et al. 2014b). In addition, in both measurement records, a strong annual cycle was observed, with clear minimum values in winter and maximum values in summer. Nevertheless, evaporation measured by pans was slightly higher (lower) during the spring and summer (winter and autumn) than that measured from Piché records. These differences were most probably due to the fact that Piché evaporimeters are shielded from solar radiation and their meas- 


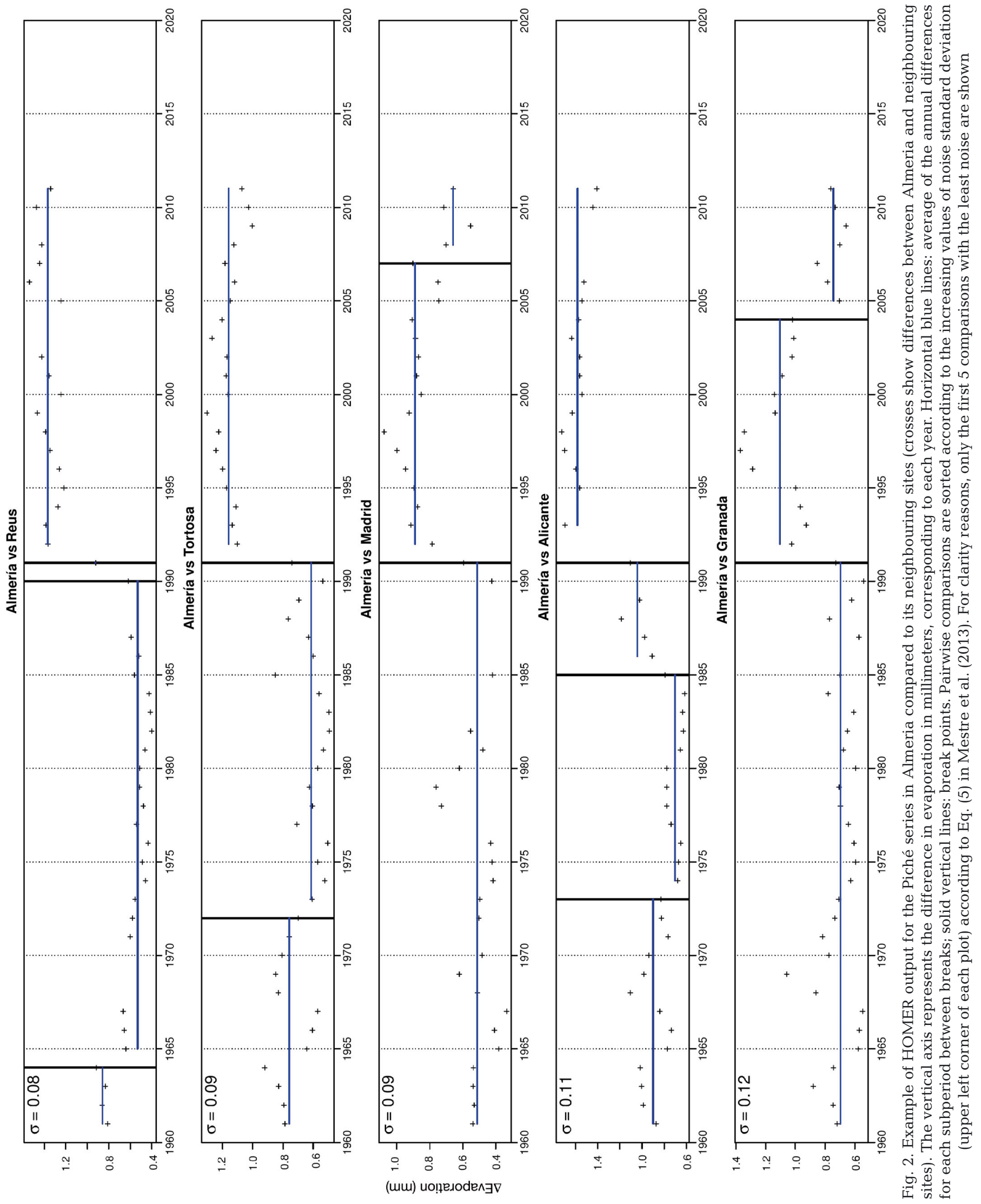


Table 2. Annual and seasonal mean values for Piché and pan evaporation measurements $\left(\mathrm{mm} \mathrm{d}^{-1}\right)$ in Spain for the period $1985-$ 2011, considering the 19 stations common to both measurements, as well as the whole set of 56 Piché series. Parentheses: interannual variability expressed as standard deviation. Note that the Piché and pan values are not strictly comparable, due to the specific characteristics of both instruments (for more details, see Section 2.1)

\begin{tabular}{|c|c|c|c|c|c|c|}
\hline & Stations & Annual & Winter & Spring & Summer & Autumn \\
\hline Pan evaporimeters & 19 & $3.85(0.21)$ & $1.55(0.18)$ & $3.95(0.28)$ & $7.02(0.47)$ & $2.88(0.22)$ \\
\hline Piché atmometers ${ }^{\mathrm{a}}$ & 19 & $3.73(0.20)$ & $1.85(0.12)$ & $3.70(0.33)$ & $6.19(0.49)$ & $3.18(0.29)$ \\
\hline Piché atmometers ${ }^{\mathrm{b}}$ & 56 & $3.90(0.20)$ & $2.13(0.14)$ & $3.89(0.30)$ & $6.19(0.47)$ & $3.39(0.26)$ \\
\hline
\end{tabular}

urements cannot be directly affected by the radiative parameters controlling evaporation, which is not the case for pan records. In fact, the differences between Piché and pan annual and seasonal mean values for all 19 sites were significant $(\mathrm{p}<0.05)$, according to a 1 -tailed $t$-test. Table 2 also shows the mean values obtained with the 56 Piché series, which were almost the same as the ones obtained with the subset of 19 Piché series (especially during the summer) with a value of around $6.2 \mathrm{~mm} \mathrm{~d}^{-1}$.

The relationship between the Piché and pan evaporation series is also seen in the scatterplot and linear regression between the monthly mean values of pan (dependent variable) and Piché (independent variable) evaporation measurements at the 19 common sites during the period 1985-2011 (Fig. 3A). $\mathrm{R}^{2}$ was $0.96(\mathrm{p}<0.01)$, with an excellent fit between values, although the points did not fall symmetrically around the diagonal line as there were slightly higher (lower) values of pan evaporation for higher (lower) evaporation rates as compared to Piché records, as mentioned above, this section. In addition, the same analysis was repeated using the mean monthly anomaly series, in order to avoid the effect of annual cycle on the results. Specifically, the monthly anomalies (obtained as differences from the 1985-2011 mean) were calculated for each of the 19 series, and, subsequently, the composite series were computed as an arithmetic mean of the 19 anomaly series. The results show (Fig. 3B) that $R^{2}$ is $0.65(p<0.01)$, which was significant, but, as expected, lower than when using the absolute monthly values; this was due to the dominant effect of the annual cycle in the time evolution of evaporation, which was removed from the anomaly series.
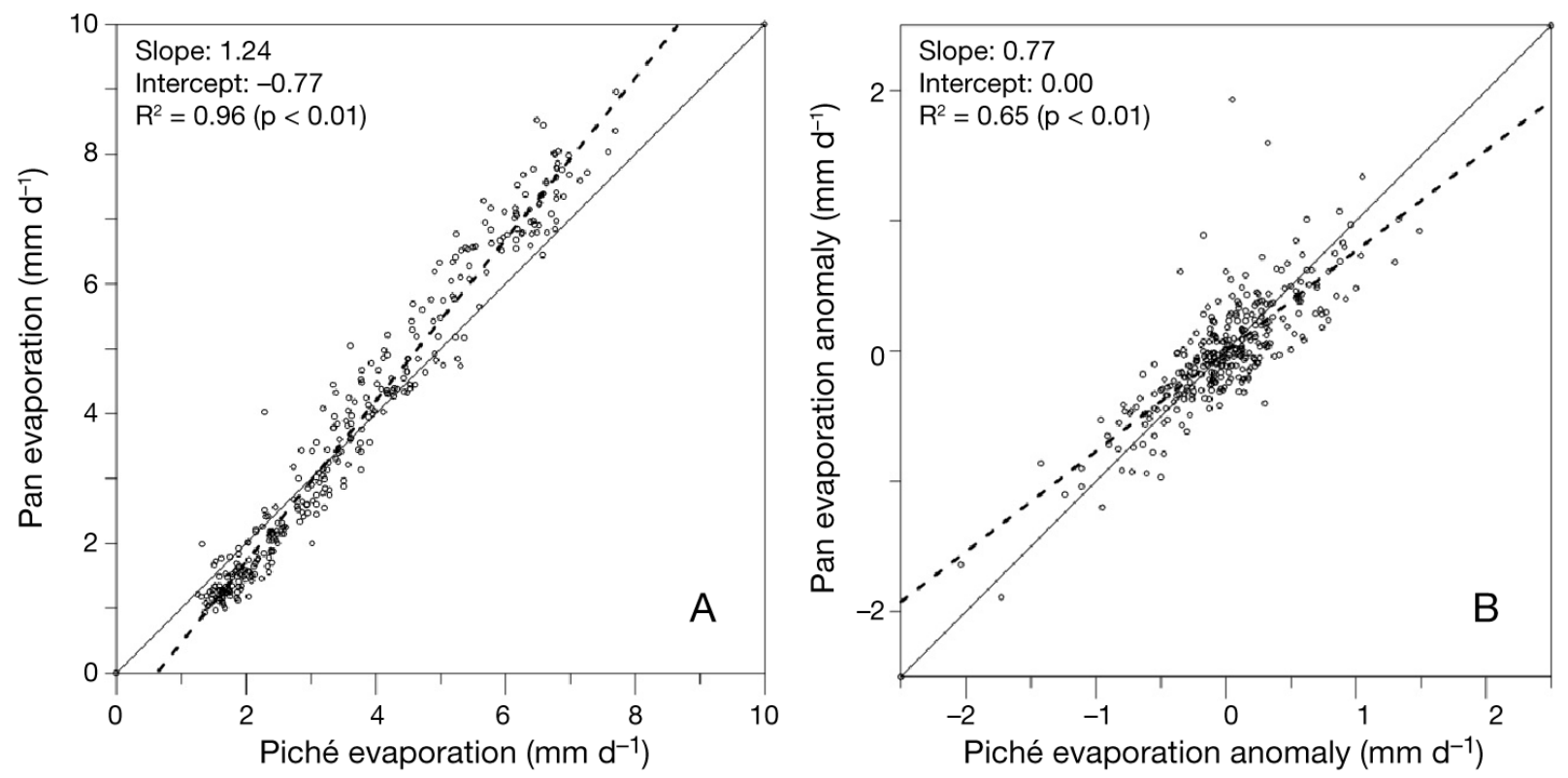

Fig. 3. (A) Scatterplot of the mean monthly values of pan and Piché evaporation in Spain for the period 1985-2011. The best fit is indicated in the plot (dashed line), together with the linear regression equations and coefficients of determination. (B) As in Panel A, but using mean monthly anomaly series expressed as differences from the 1985-2011 mean. Solid line: theoretically perfect agreement between both measurements 


\subsection{Comparison of the trends}

The time evolution of evaporation during the common period 1985-2011 was compared on an annual and seasonal basis for the subset of 19 series with Piché and pan evaporation series. On an annual basis (Fig. 4), both time series showed similar interannual evolution $\left(\mathrm{R}^{2}=0.63\right)$ and exhibited an increase in evaporation during the study period. Specifically, the rate of increase was $+0.10 \mathrm{~mm} \mathrm{~d}^{-1}$ decade $^{-1}(95 \%$ confidence interval: $+0.00,+0.18)$ and $+0.08 \mathrm{~mm} \mathrm{~d}^{-1}$ decade $^{-1}(95 \%$ confidence interval: $0.00,+0.20)$ for the Piché and pan evaporation series, respectively.

On a seasonal basis (Fig. 4), the high values of the coefficient of determination in spring, summer and autumn, which were around 0.70, were in contrast with the lower value obtained in winter, possibly due to the lower interannual variability of this seasonal series and limitations on the measurements during this part of the year (i.e. the water in tubes and pans can freeze). Fortunately, the winter season contributed least to annual estimates due to the lower rates of evaporation (Table 2), and the impact on annual trends was of minor importance. In fact, the mean summer series was that most similar to the annual series previously described, as expected, due to the larger values of summertime evaporation, and thus the largest contribution to the annual mean. In addition, the greatest increase in evaporation was observed in summer; this increase was found in both types of measurements, with a very similar magnitude of change. Specifically, an increase of $+0.27 \mathrm{~mm}$ $\mathrm{d}^{-1}$ decade $^{-1}$ (95\% confidence interval: $+0.03,+0.53)$ and $+0.27 \mathrm{~mm} \mathrm{~d}^{-1}$ decade $^{-1}(95 \%$ confidence interval: $+0.09,+0.46)$ was observed for Piché and pan evaporation series, respectively.

Summarizing the results in Sections 3.1 and 3.2, it seems plausible that, at least for Spain, the measurements of Piché evaporation can capture the same or very similar patterns of interannual and decadal evolution as those found using pan evaporation data, even considering the fact that both measurement methods were not directly comparable in absolute terms. Therefore, taking into account the limited number of stations reporting pan evaporation, as well as the brevity of their records, it is highly recommended, at least for Spain, to also consider the changes in evaporation demand by means of the available long-term Piché series. In fact, no studies exist reporting the annual or seasonal trends in Piché records versus those in pan evaporation series, since, to our knowledge, only few attempts have been made to relate Piché with pan evaporation measurements and/or evaporation estimates and, where attempted, this was only done on a short-term basis (e.g. Stanhill 1962, Jacobs \& Linclaen Arriëns-Bekker 1983, Papaioannou et al. 1998).
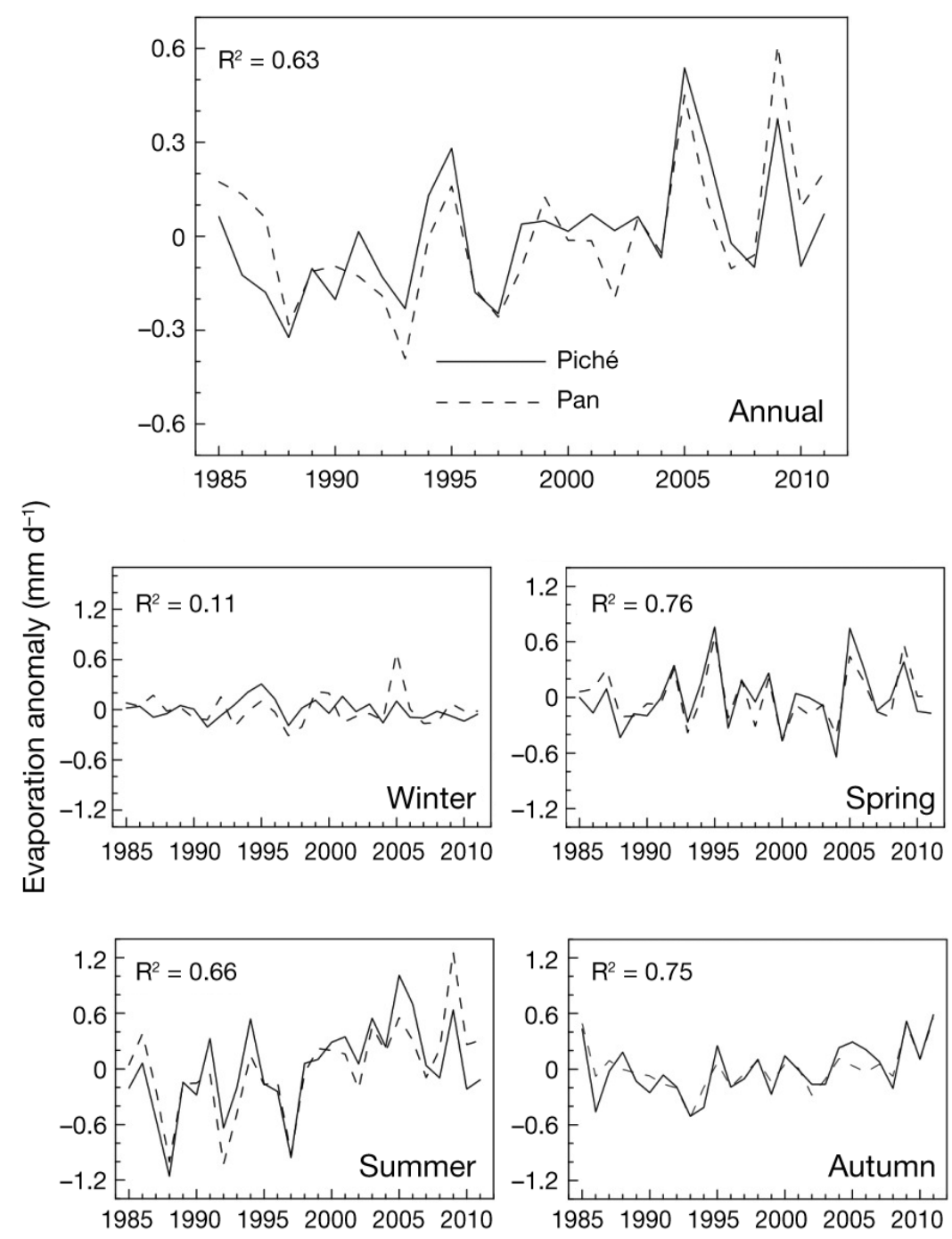

Fig. 4. Mean annual and seasonal Piché (solid line) and pan (dashed line) evaporation series from 1985 to 2011. The series are expressed as anomalies from the 1985-2011 mean, and are constructed using the subset of 19 stations with collocated records for the 2 measurement techniques. The coefficients of determination between the series are indicated in the plot 


\section{LONG-TERM TRENDS OF PICHÉ SERIES}

In order to study the long-term evolution of the evaporation in Spain before the 1980s, the full homogeneous dataset of Piché measurements was used. Thus, all 56 series with records since 1961 will now be considered. The annual and seasonal anomalies were calculated first for each homogenized Piché series from 1961 to 2011, and again considering 1985-2011 as the reference period. Afterwards, annual and seasonal mean series were computed. The linear trends of the series obtained over the period 1961-2011 and the subperiods 1961-1984 and 19842011 are shown in Table 3.

The annual Piché series (Fig. 5) showed a slight increase during the first half of the 1960s, followed by a decrease until the mid-1980s. There was a clear change in the series around 1984, when the absolute minimum of the filtered series was observed. Afterwards, there was a tendency towards an increase from the late 1980s until the mid-2000s (with a maximum in 2005) that almost compensated for the previous decrease, ending with a slight decrease during the last years of the study period. The linear trend, estimated over the 19612011 period, was non-significant. When the series was subdivided into the 1961-1984 and 1985-2011 subperiods, the linear trends were significantly negative $\left(-0.14 \mathrm{~mm} \mathrm{~d}^{-1}\right.$ decade $\left.^{-1}\right)$ and positive $\left(+0.15 \mathrm{~mm} \mathrm{~d}^{-1}\right.$ decade $\left.^{-1}\right)$, respectively.

On a seasonal basis (Fig. 5), the interannual and decadal variability of the spring and summer series were most similar to the annual series. In addition, in both seasons, there were significant negative and positive trends during the 2 subperiods. Nevertheless, a clear difference was evident in summer, as the magnitude of the increase since the 1980s was greater than the previous decrease. Consequently, there was a significant and positive trend of $+0.07 \mathrm{~mm} \mathrm{~d}^{-1}$ decade $^{-1}$ for summer over the period 1961-2011.

The autumn series differed from the annual series as it started with a slight increase until the mid-1970s, with a
Table 3. Annual and seasonal trends, calculated using Sen's trend estimator, for the Piché mean series in Spain, over the period 1961-2011 and the 1961-1984 and 1985-2011 subperiods. Bold, regular and italic numbers indicate trends with significance levels higher than 99, 95 and $90 \%$, respectively; ns: not significant. The values are expressed in $\mathrm{mm} \mathrm{d}^{-1}$ decade $^{-1}$. Parentheses: trends expressed in $\mathrm{mm} \mathrm{yr}^{-1}$ decade $^{-1}$ and in mm season ${ }^{-1}$ decade $^{-1}$ for the annual and seasonal series, respectively

\begin{tabular}{|lccc|}
\hline & $1961-1984$ & $1985-2011$ & $1961-2011$ \\
\hline Annual & $-0.14(-52.5)$ & $\mathbf{+ 0 . 1 5 ( + 5 4 . 8 )}$ & $\mathrm{ns}$ \\
Winter & $\mathrm{ns}$ & $\mathrm{ns}$ & $\mathbf{- 0 . 0 6}(\mathbf{- 5 . 1})$ \\
Spring & $-0.20(-18.6)$ & $+0.13(+11.5)$ & - \\
Summer & $\mathbf{- 0 . 2 8 ( - 2 5 . 8 )}$ & $+0.30(+27.8)$ & $+0.07(+6.3)$ \\
Autumn & $\mathrm{ns}$ & $+0.14(+12.5)$ & $\mathrm{ns}$ \\
\hline
\end{tabular}

Fig. 5. Mean annual and seasonal Piché evaporation series (thin line) from 1961 to 2011, plotted together with an 11 yr Gaussian low-pass filter (thick line). The series are expressed as anomalies from the 1985-2011 mean, and were constructed using the 56 available Piché series. Thin dashed lines show the mean Piché series obtained using the subset of 19 stations with collocated pan records, as used in Fig. 2 
subsequent decrease that ended in the early 1990s. Equally, there was no evidence of a decrease since the mid-2000s, as observed in the annual series. Finally, the winter series showed an intriguing significant decrease of $-0.06 \mathrm{~mm} \mathrm{~d}^{-1}$ decade $^{-1}$ when the whole study period was considered. This result may be called into question due to the lower reliability of the Piché measurements during winter as commented in Section 3.2.

Fig. 5 also includes the mean Piché series using the 19 stations with collocated pan evaporation records, i.e. the series used in Fig. 4 but over the whole 19612011 period. The series showed that the subset of stations captured almost the same interannual and decadal variability as did that considering all series, possibly due to the strong spatial autocorrelation in evaporation series. Consequently, it was possible to describe the time evolution of evaporation in Spain by means of a limited number of stations. Specifically, the $\mathrm{R}^{2}$ between both mean annual series was 0.90 , and for the seasonal series it ranged between a minimum and maximum of 0.83 and 0.94 in winter and summer, respectively.

\section{DISCUSSION}

In contrast with this study, most of the scientific literature shows a widespread decrease of pan evaporation during the last decades (Fu et al. 2009), with an average trend of around $-0.09 \mathrm{~mm} \mathrm{~d}^{-1}$ decade $^{-1}$ (for review see McVicar et al. 2012). Nevertheless, in the Mediterranean region, an increase in pan evaporation since the 1970s has been reported, for example over Greece (McVicar et al. 2012) and Israel (Cohen et al. 2002), in consonance with the significant increase observed in the present study in Spain since the 1980s. Equally, this increase in pan evaporation is also in line with a widespread increase in potential evaporation reported over the Mediterranean since the 1980s (e.g. Matsoukas et al. 2011, Papaioannou et al. 2011, for review see Vicente-Serrano et al. 2014b).

Also, over Europe, a decrease from the 1960s to the 1980 s, with a subsequent increase up to the 2000s, was observed in both pan evaporation data at Valentia in Ireland (Black et al. 2006) and evapotranspiration estimates in Central Europe (Teuling et al. 2009), in agreement with the decadal evolution observed in Spain since the 1960s. Moreover, the trends in $\mathrm{ET}_{0}$ reported over Spain (Vicente-Serrano et al. 2014b) are similar to the changes observed here using Piché and pan evaporation series. Specifically, using Piché series a significant increase of $6.3 \mathrm{~mm}$ decade $^{-1}$ was found in summer in the present study, which is in line with the increase in $\mathrm{ET}_{0}$ of around $10 \mathrm{~mm}$ decade ${ }^{-1}$ reported by Vicente-Serrano et al. (2014b) using the Penman-Monteith equation for the same period (1961-2011).

The decadal variations in Piché evaporation also agreed with the sunshine duration series over Spain (Sanchez-Lorenzo et al. 2009). The important role of surface solar radiation to drive evaporation is well known, and, consequently, a link between the dimming/brightening phenomenon (Wild 2009) and the trends in actual and potential evaporation has been shown in previous studies (Roderick \& Farquhar 2002, Wild et al. 2008, Teuling et al. 2009, Fu et al. 2009, Papaioannou et al. 2011). In fact, both solar radiation (Sanchez-Lorenzo et al. 2013) and Piché and pan trends in Spain since the mid-1980s seem to agree, not only qualitatively, but also quantitatively. Indeed, an increase in evaporation of around $+0.4 \mathrm{~mm} \mathrm{~d}^{-1}$ was found over the whole $27 \mathrm{yr}$ period (1985-2011); this rate corresponded to an average of about $12 \mathrm{~mm} \mathrm{mo}^{-1}$ or $12 \mathrm{~W} \mathrm{~m}^{-2}$ of additional energy consumed by evaporation over this period, as estimated using the latent heat of evaporation of water. This estimation of the energy of evaporation is in line with the significant increase in surface solar radiation in Spain of $+3.9 \mathrm{~W} \mathrm{~m}^{-2}$ decade $^{-1}$ since the mid-1980s (Sanchez-Lorenzo et al. 2013), which corresponds to around $10.5 \mathrm{~W} \mathrm{~m}^{-2}$ if the $27 \mathrm{yr}$ period of this study is considered.

Nevertheless, this agreement needs attention, as Piché evaporimeters are inside meteorological screens and not directly exposed to radiation. Thus, as Piché readings are mainly affected by the aerodynamic term in Penman's evaporation equation (e.g. Penman 1948, Stanhill 1962) and pan records are affected by both the heat balance and aerodynamic terms, the results of this study suggest that both terms must be highly and positively correlated in Spain. In order to check this hypothesis, the radiative and aerodynamic components were estimated over the whole of Spain for the 19 locations with records of Piché and pan evaporation. Specifically, all variables that are needed to calculate evaporation (Allen et al. 1998) using the modified and adapted Penman's equation (Shuttleworth 1993) were extracted from homogenous records of temperature and relative humidity (Vicente-Serrano et al. 2014a), wind speed (Azorin-Molina et al. 2014) and sunshine duration (Sanchez-Lorenzo et al. 2007). For more details, we refer to Vicente-Serrano et al. (2014b). The results show that both compo- 
nents are moderately correlated over the 1985-2011 period $(\mathrm{R}=0.68, \mathrm{p}<0.05)$. In addition, it should be noted that the relationship with the radiative components is weaker than that with the aerodynamic component for both pan and Piché evaporation measurements. Specifically, the correlation coefficients of the radiative term are 0.78 and 0.58 for the Piché and pan evaporation series, respectively, whereas, for the aerodynamic term, both variables show higher values $(R=0.86$ for Piché, $R=0.87$ for pan evaporation). In addition, both annual mean component series show an increase during the period 1985-2011 (Fig. 6), but the aerodynamic term is larger $\left(+18.4 \mathrm{~mm}[+1.9 \%]\right.$ decade $^{-1}, \mathrm{p}<$ $0.01,95 \%$ confidence interval of $[+8.2,+31.7] \mathrm{mm}$ decade $\left.^{-1}\right)$ than the radiative term $(+14.6 \mathrm{~mm}$ [+3.7\%] decade ${ }^{-1}, \mathrm{p}<0.05,95 \%$ confidence interval of $[+3.6,+14.4] \mathrm{mm}$ decade $^{-1}$ ). These results indicate that the increase in evaporation over Spain since the mid-1980s can be related to changes in both terms of the Penman-Monteith equation, especially the aerodynamic component, possibly due to a strong decrease in relative humidity in the last decades (Vicente-Serrano et al. 2014a) and a noticeable increase in air temperature (Brunet et al. 2007). Nevertheless, the possible role of water vapor deficit and temperature changes, which can be modulated by surface solar radiation variations (Wang \& Dickinson 2013, E. van den Besselaar et al. unpubl. data), must be explored in detail in order to explain these trends in evaporation over Spain. Thus, further research is needed to evaluate this hypothesis and the relationship of the different aerodynamic and radiative terms with the Piché

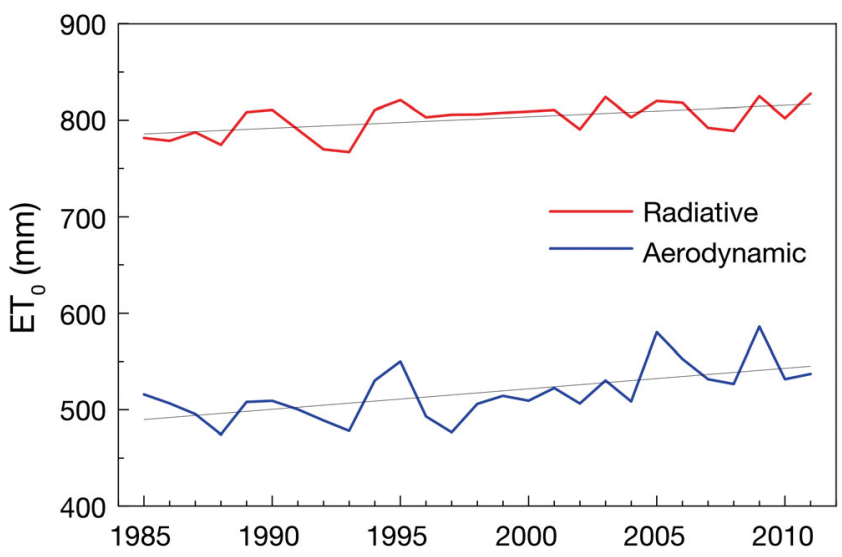

Fig. 6. Mean annual radiative (red line) and aerodynamic (blue) components of $\mathrm{ET}_{0}$ (reference evapotranspiration) in Spain for the 19 locations with records of Piché and pan evaporation, as estimated by the Penman equation, from 1985 to 2011. Linear regressions shown by thin gray lines and pan evaporation series for different regions of Spain, as well as using different models to calculate evaporation estimates (e.g. the PenPan model, etc.), which is beyond the scope of this article.

Overall, the Piché series have the potential to extend our knowledge of past changes in potential evaporation due to their long-term measurements in countries such as Spain. It is worth noting that few studies have reported evaporation trends since the 1960 s, due to the scarcity of long-term series of pan evaporation (McVicar et al. 2012). In fact, to our knowledge only one study has reported trends in potential evaporative demand before the 1960s by using 8 series in the UK with records from the 1880s to the 1960s measured with the standard British Meteorological Office tank (Stanhill \& Markus 2008).

The suitability of Piché records to go back in time as compared to pan evaporation data in Spain is highlighted again in Fig. 7, which shows the mean series using the 11 stations (Alicante, Barcelona, Castellón, Córdoba, Girona, Madrid-Retiro, San Sebastián, Toledo, Valencia, Valladolid and Vitoria) with digitalized records starting before the 1940s. The large number of gaps and low number of stations with records prior to this decade, force us to limit this example to the period 1941-2011. The most interesting feature of Fig. 7 is the sharp increase in the potential evaporation observed in the mid-1940s, which interestingly, is in line with an increase reported over the UK by Stanhill \& Markus (2008) by using pan evaporation measurements, as well as with the early brightening reported over Europe by using global solar radiation and sunshine duration data (Sanchez-Lorenzo et al. 2008, Ohmura 2009, Wild 2009). This result highlights the need for further research, in order to digitize and homogenize the longest Piché series since the mid-19th century in Spain and other regions of the world.

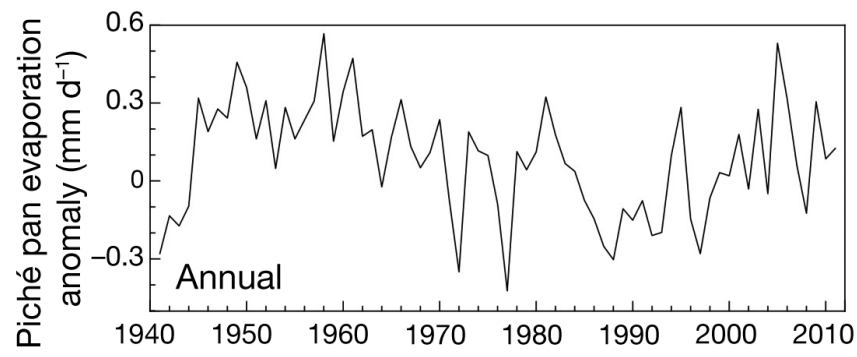

Fig. 7. Mean annual Piché evaporation series from 1941 to 2011. The series is expressed as anomaly from the 19852011 mean, and constructed using the 11 longest Piché series, available since the 1940 s 


\section{CONCLUSIONS}

There is a growing interest in the trends of atmospheric evaporation demand, enhancing the need for long-term time series. In this study, a dataset of Piché (pan) evaporation measurements in Spain is described, for the first time, based on records available since the 1940s (1980s). Special attention was placed on the assessment of the homogeneity of the records.

A comparison of Piché evaporation series with pan evaporation series was performed using data from 19 stations with collocated measurements. The results highlight a moderately good agreement between these 2 measurement methods regarding their climatological means. Furthermore, the mean series for both variables show similar interannual and decadal variations, especially during summer, when evaporation contributes a large portion to the annual total. Consequently, the Piché series has proven, at least in Spain, to be a good measure for estimating the potential evaporative demand, and enables us to enhance the spatial and temporal resolution of pan data in the areas with long-term records using Piché evaporimeters.

An analysis of long-term Piché series in Spain was performed from 1961 to 2011. The mean annual series showed a significant trend with a decrease (increase) in evaporation from the 1960s to mid1980s (since the 1980s), which combined produced an overall non-significant trend over the whole study period. In summer, a significant increase was found. These findings are in line with trends of reference evapotranspiration in Spain and worldwide trends of surface solar radiation.

Overall, this study provides a unique evaporation dataset over Spain to study trends in this variable since the mid-20th century. Evaporation is a crucial variable to better understand the hydrological cycle and other processes linked to changes in vegetation or agriculture, for example. Further research is needed in order to relate Piché records to estimates of $\mathrm{ET}_{0}$ in Spain and other worldwide locations where long-term Piché series are available (e.g. Stanhill 1962, Jacobs \& Linclaen Arriëns-Bekker 1983, Papaioannou et al. 1996). With such further research, it will be possible to reconstruct the evaporative demand since the beginning of the Piché observations, some of them more than a century ago. In order to achieve this goal, an effort to digitize Piché series since the mid-19th century is needed.

The dataset developed here on an annual and seasonal basis is available on request (arturo.sanchez@ udg.edu, svicen@ipe.csic.es, josep.calbo@udg.edu).
Acknowledgements. This work has been supported by the research projects CGL2010-17172/BOS, CGL2011-27574CO2-02, CGL2011-27536, CGL2010-18456 and ConsoliderIngenio Montes CSD2008-00040 financed by the Spanish Commission of Science and Technology and FEDER; 'Demonstration and validation of innovative methodology for regional climate change adaptation in the Mediterranean area (LIFE MEDACC)' financed by the LIFE programme of the European Commission; and SGR 2009-458 financed by the Catalan Government. A.S.L. was supported by the 'Secretaria per a Universitats i Recerca del Departament d'Economia i Coneixement, de la Generalitat de Catalunya i del programa Cofund de les Accions Marie Curie del 7è Programa marc d'R+D de la Unió Europea' (2011 BP-B 00078) and the postdoctoral fellowship No. JCI2012-12508. C.A.M. was given a grant by the 'Juan de la Cierva' programme (JCI-2011-10263) of the MICINN. We thank AEMET for providing the evaporation data.

\section{LITERATURE CITED}

Abtew W, Obeysekera J, Iricanin N (2011) Pan evaporation and potential evapotranspiration trends in South Florida. Hydrol Processes 25:958-969

Allen RG, Pereira LS, Raes D, Smith M (1998) Crop evapotranspiration-Guidelines for computing crop water requirements. FAO irrigation and drainage paper 56, FAO, Rome

Azorin-Molina C, Vicente-Serrano SM, McVicar TR, Jerez S and others (2014) Homogenization and assessment of observed near-surface wind speed trends over Spain and Portugal, 1961-2011. J Clim 27:3692-3712

> Black K, Davis P, Lynch P, Jones M, McGettigan M, Osborne B (2006) Long-term trends in solar irradiance in Ireland and their potential effects on gross primary productivity. Agric Meteorol 141:118-132

Brunet M, Jones PD, Sigró J, Saladié O and others (2007) Temporal and spatial temperature variability and change over Spain during 1850-2005. J Geophys Res 112: D12117, doi:10.1029/2006JD008249

Brutsaert W, Parlange MB (1998) Hydrologic cycle explains the evaporation paradox. Nature 396:30

Cohen S, Ianetz A, Stanhill G (2002) Evaporative climate changes at Bet Dagan, Israel, 1964-1998. Agric Meteorol 111:83-91

> De Vries D, Venema HJ (1954) Some considerations on the behaviour of the Piche evaporimeter. Vegetatio 5-6: $225-234$

Doorenbos J, Pruitt WO (1977) Crop water requirements. FAO irrigation and drainage paper No. 24, FAO, Rome

$>$ Fu G, Charles SP, Yu J (2009) A critical overview of pan evaporation trends over the last 50 years. Clim Change 97:193-214

Hobbins MT, Ramírez JA, Brown T (2004) Trends in pan evaporation and actual evapotranspiration across the conterminous US: paradoxical or complementary? Geophys Res Lett 31:L13503, doi:10.1029/2004GL019846

Jacobs AF, Linclaen Arriëns-Bekker E (1983) Evaporation data from a Piche evaporimeter. J Hydrol (Amst) 60: 367-380

Jovanovic B, Jones DA, Collins D (2008) A high-quality monthly pan evaporation dataset for Australia. Clim Change 87:517-535

> Linacre ET (1977) A simple formula for estimating evaporation rates in various climates, using temperature data alone. Agric Meteorol 18:409-424 
Matsoukas C, Benas N, Hatzianastassiou N, Pavlakis KG, Kanakidou M, Vardavas I (2011) Potential evaporation trends over land between 1983-2008: driven by radiative fluxes or vapour-pressure deficit? Atmos Chem Phys 11: 7601-7616

McMahon TA, Peel MC, Lowe L, Srikanthan R, McVicar TR (2013) Estimating actual, potential, reference crop and pan evaporation using standard meteorological data: a pragmatic synthesis. Hydrol Earth Syst Sci 17:1331-1363

McVicar TR, Roderick ML, Donohue RJ, Li LT and others (2012) Global review and synthesis of trends in observed terrestrial near-surface wind speeds: implications for evaporation. J Hydrol (Amst) 416-417:182-205

Mestre O, Domonkos P, Picard F, Auer I and others (2013) HOMER: a homogenization software-methods and applications. Q J Hungarian Meteorol Serv 117:47-67

Ohmura A (2009) Observed decadal variations in surface solar radiation and their causes. J Geophys Res 114: D00D05, doi:10.1029/2008JD011290

Papaioannou G, Vouraki K, Kerkides P (1996) Piche evaporimeter data as a substitute for Penman equation's aerodynamic term. Agric Meteorol 82:83-92

Papaioannou G, Kaloudis S, Kerkides P (1998) On the proper employment of Piche evaporimeters in estimating evapotranspiration. Int J Climatol 18:1247-1260

Papaioannou G, Kitsara G, Athanasatos S (2011) Impact of global dimming and brightening on reference evapotranspiration in Greece. J Geophys Res 116:D09107, doi: 10.1029/2010JD015525

Penman HL (1948) Natural evaporation from open water, bare soil, and grass. Proc R Soc Lond A Math Phys Sci 193:120-145

Peñuelas J, Sardans J, Estiarte M, Ogaya R and others (2013) Evidence of current impact of climate change on life: a walk from genes to the biosphere. Glob Change Biol 19: 2303-2338

Peterson TC, Golubev VS, Groisman PY (1995) Evaporation losing its strength. Nature 377:687-688

Peterson TC, Easterling DR, Karl TR, Groisman P and others (1998) Homogeneity adjustments of in situ atmospheric climate data: a review. Int J Climatol 18:1493-1517

Prescott JA, Stirk GB (1951) Studies on the Piche evaporimeter. Austr J Appl Sci 2:243-256

Roderick ML, Farquhar GD (2002) The cause of decreased pan evaporation over the past 50 years. Science 298: 1410-1411

Roderick ML, Farquhar GD (2004) Changes in Australian pan evaporation from 1970 to 2002. Int J Climatol 24: 1077-1090

Sanchez-Lorenzo A, Brunetti M, Calbó J, Martin-Vide J (2007) Recent spatial and temporal variability and trends of sunshine duration over the Iberian Peninsula from a homogenized data set. J Geophys Res 112:D20115, doi: 10.1029/2007JD008677

Editorial responsibility: Oliver Frauenfeld, College Station, Texas, USA
Sanchez-Lorenzo A, Calbó J, Martin-Vide J (2008) Spatial and temporal trends in sunshine duration over western Europe (1938-2004). J Clim 21:6089-6098

Sanchez-Lorenzo A, Calbó J, Brunetti M, Deser C (2009) Dimming/brightening over the Iberian Peninsula: trends in sunshine duration and cloud cover and their relations with atmospheric circulation. J Geophys Res 114: D00D09, doi:10.1029/2008JD011394

> Sanchez-Lorenzo A, Calbó J, Wild M (2013) Global and diffuse solar radiation in Spain: building a homogeneous dataset and assessing their trends. Global Planet Change 100:343-352

> Sen PK (1968) Estimates of the regression coefficient based on Kendall's tau. J Am Stat Assoc 63:1379-1389

Shuttleworth WJ (1993) Evaporation, Chapter 4. In: Maidment DR (ed) Handbook of hydrology. McGraw-Hill Inc., New York, NY

- Stanhill G (1962) The use of the Piche evaporimeter in the calculation of evaporation. QJR Meteorol Soc 88:80-82

Stanhill G, Markus M (2008) Evaporative climate change in the British Isles. Int J Climatol 28:1127-1137

> Teuling AJ, Hirschi M, Ohmura A, Wild M and others (2009) A regional perspective on trends in continental evaporation. Geophys Res Lett 36:L02404, doi:10.1029/2008GL 036584

Venema VKC, Mestre O, Aguilar E, Auer I and others (2012) Benchmarking homogenization algorithms for monthly data. Clim Past 8:89-115

> Vicente-Serrano SM, Beguería S, López-Moreno JI, GarcíaVera MA, Stepanek P (2010) A complete daily precipitation database for northeast Spain: reconstruction, quality control, and homogeneity. Int J Climatol 30:1146-1163

Vicente-Serrano SM, Azorin-Molina C, Sanchez-Lorenzo A, Morán-Tejeda E and others (2014a) Temporal evolution of surface humidity in Spain: recent trends and possible physical mechanisms. Clim Dyn 42:2655-2674

Vicente-Serrano SM, Azorin-Molina C, Sanchez-Lorenzo A, Revuelto J and others (2014b) Reference evapotranspiration variability and trends in Spain, 1961-2011. Glob Planet Change 121:26-40

> Wang K, Dickinson RE (2013) Contribution of solar radiation to decadal temperature variability over land. Proc Natl Acad Sci USA 110:14877-14882

Wild M (2009) Global dimming and brightening: a review. J Geophys Res 114:D00D16, doi:10.1029/2008JD011470

Wild M, Grieser J, Schär C (2008) Combined surface solar brightening and increasing greenhouse effect support recent intensification of the global land-based hydrological cycle. Geophys Res Lett 35:L17706, doi:10.1029/2008 GL034842

WMO (World Meteorological Organization) (2008) Chapter 10. Measurement of evaporation. In: Guide to meteorological instruments and methods of observation. WMO, Geneva

Submitted: January 23, 2014; Accepted: July 22, 2014 Proofs received from author(s): October 9, 2014 